\title{
Factors affecting English Language Learning Motivation of Korean Freshmen and their General Characteristics
}

\author{
Weon-Hee Moon, Ok-Hee Park
}

\begin{abstract}
Affective factors are crucial to acquire ESL (English as a second language) or EFL (English as a foreign language) learning. This study aims to investigate factors affecting to Korean university freshmen's English learning motivation and their general characteristics such as gender, major and exposure to English. 379 freshmen at a regional university in Korea participated in the survey. They registered in a mandatory communicative English class managing by team-teaching with native speakers and Korean professors. The survey format was a descriptive and direct method, and composed with two parts, one is a check list asking for general characteristics and exposure to English, and the other is a 5Likert scale asking for participant's interest, expectation, confidence, motivation, and anxiety. Motivation was used as a dependent variable, and the others were used as affective factors for motivation. Collected data was analyzed with SPSS statistics. There was not statistical significance depending on gender in all affective factors. As for major, there showed statistical significance in confidence and anxiety factors $(p<.05)$. Natural Science \& Engineering (NSE) majoring students' confidence was highest, and that of Human and Social Sciences (HSS) and Art, Music \& Physical education (AMP) majoring students was followed. As for anxiety, NSE students were lowest, HSS students and AMP students were followed. As for exposure to English, there showed statistical significance in interest, confidence, motivation, and anxiety factors $(p<.05, p<.01)$. Students with learning experience with native speakers (NS) were higher interest, confidence, and motivation, and lower anxiety than students with none of exposure in English. Meanwhile, NS students showed lower interest and anxiety, and higher confidence than students with abroad experience. In relationship between affective factors, the most influential factor for learning motivation was confidence, expectation, and interest in order $(p<.05)$.The results are expected to provide basic data necessary for establishing and developing an efficient and systematic communicative English education program.
\end{abstract}

Keywords: English learning motivation, Affective factors, Team-teaching, EFL learners, learning experience with native speakers.

\section{INTRODUCTION}

$\mathrm{W}$ ith the globalization and the development of information technology, the importance of English has been tremendously growing. Nowadays, English language education is considered as one of crucial tools for one's

Revised Manuscript Received on July 22, 2019.

Weon-Hee Moon, Department of Nursing Science, Pai Chai University, Daejeon, 35345, South Korea. Email: whmoon@ pcu.ac.kr

Ok-Hee Park, Correspondence Author,Liberal Arts Department, Pai Chai University, 35345, Korea. Email: okpark@ pcu.ac.kr success in business or career. To meet the requirements of current situation, most universities in Korea have been trying to provide better foreign language education programs with students. In spite of the efforts, many Korean students have been struggling with English learning. For Korean students learning English as a foreign language, affective factors could hinder the language acquisition besides cognitive factors and socio-cultural ones.

Krashen [1] insisted affective factors such as interest, motivation, confidence, anxiety to succeed in target language acquisition in his 'affective filter hypothesis.' He claimed to provide optimal input condition to learners as lowering anxiety, and increasing motivation and confidence. For the study in affective domain, Gardner \& Lambert's theory [2] has been also noticeable. Gardner \& Lambert [2] paid attention especially for motivation, and explained it in two ways, one is an 'integrative motivation', which orients to be absorbed in other cultures and to interact as their community members. The other is an 'instrumental motivation', which aims to learn foreign languages for practical purpose such as getting a job or promotion. Recently, Dörnyei\&Ushioda [3] have explained that affective filters ought to broaden into learners' environmental and temporal factors to succeed in his 'L2 learning self-system theory'.

Following the overseas theoretical researches, many studies for affective factors have been stimulated domestically. They have mainly focused on finding out a more influential factor affecting English accomplishment or comparison between various affective factors for elementary school students through university students [4-10]. Affective factors which researchers emphasize more crucial in English learning for Korean students are diverse, but the debate has not reached a consensus yet [6].

This study aims to investigate whether the affective factors work differently depending on gender, major, exposure to English for students at a regional university in Korea, and relationship between affective factors and which one is more influential to learning motivation. The study will be meaningful to investigate for university freshmen, in regard to studies for university students were relatively not many, and to be able to suggest more appropriate teaching method according to students' characteristics and more influential factors on learning motivation. 


\section{MATERIAls AND MethodS}

\section{A.Study design}

This is a descriptive survey study to find out factors affecting English learning depending on gender, major, and exposure to English, and investigate relationship between affective factors and find out which factor is more influential to learning motivation.

\section{B.Subjects}

403 freshmen, who registered in the mandatory English communicative class managing by team-teaching with native speakers and Korean professors, participated in the survey on the second week of 2018 spring semester. However, insufficient or inappropriate responses were excluded, and $379(94.0 \%)$ responses were used for research data.

\section{C.Measurements}

The survey questionnaire was composed with two parts. One part is a check list to find out students' general characteristics such as gender, major, and exposure to English. The other part is made of 24 questions based on the 5Likert scale for gauging students' affective factors such as interest (Q1-5), expectation (Q6-10), confidence (Q11-14), motivation (Q15-20), and anxiety (Q21-24). These affective factors are called 'IECMA' in this study. The survey questionnaires were modified based on the study by Kim \& Lee [11]. A pilot test with 80 students in enrolled at the communicative English class was performed to verify the reliability of the revised study. The result shows that Cronbach's $\alpha$ was over 0.700 in every domain. On 5Likert scale, 1 means "strongly disagree", and 5 means "strongly agree".

\section{D.Data analysis method}

Collected data were analyzed using the IBM SPSS Statistics Version 22 program. Specifically, frequency, independent sample t-test, one-way ANOVA were used for a descriptive statistics and difference analysis of IECMA depending on participants' general characteristics. For post hoc analysis of one-way ANOVA, LST and DunnettT3 procedure were used. A multiple linear regression was used to find out which factors affect learning motivation.

\section{RESULTS AND DISCUSSION}

\section{A.General characteristics}

In terms of participant's general characteristics, $186(49.1 \%)$ were male students and $193(50.9 \%)$ were female students. With respect to the major, 189(49.8\%) were Natural Sciences \& Engineering (NSE), 159(42.0\%) were Humanities and Physical education (AMP). For Exposure to English, $94(24.8 \%)$ had none of learning experience with native speakers or abroad, 242(63.8\%) had learning experience with native speakers, $6(1.6 \%)$ had studying abroad, and 37(9.8\%) had experience both native speakers and abroad.

B.Differences in variables IECMA factors depending on participants' gender, major, and exposure to English

To identify mean difference of IECMA depending on and Social Science (HSS), and 31(8.2\%) were Arts, Music \&

general characteristics, independent t-test and one-way ANOVA were used. For multiple comparison post-hoc analysis, LSD test was used for equality of variances, and DunnettT3 procedure was used in case Levene's hypothesis was not valid.

\section{C.Mean score differences in IECMA factors depending on gender}

As shown table 1, the mean score in interest factor depending on gender showed that female ( $3.79 \pm 0.68$ point) was higher than male $(3.64 \pm 0.79$ point $)$, but there was not statistically significant $(\mathrm{t}=-1.935, \mathrm{p}=.054)$. The mean score in expectation factor showed that male $(3.37 \pm 0.89$ point $)$ was a little bit higher than female $(3.36 \pm 0.84$ point $)$, but there was not statistically significant $(\mathrm{t}=0.164, \mathrm{p}=.087)$. The mean score in confidence factor was same both male and female $(3.60 \pm 0.96,3.60 \pm 0.81$ point $)$, and there was not statistically significant difference $(\mathrm{t}=-0.018, \mathrm{p}=.098)$. The mean score in motivation factor showed that female $(4.25 \pm 0.73$ point $)$ was higher than male $(4.16 \pm 0.77$ point), but there was not statistically significant ( $\mathrm{t}=-1.107, \mathrm{p}=.269)$. The mean score in anxiety factor showed that male $(2.48 \pm 1.12$ point $)$ was a little higher than female $(2.45 \pm 1.10$ point $)$, but there was not statistically significant $(\mathrm{t}=0.244, \mathrm{p}=.808)$.

Meanwhile, Kang's research [4] showed a statistically significant result that female students have higher motivation than male students.

\section{D.Mean score differences in IECMA factors depending on major}

As shown table 1, the result of analyzing difference in mean score of interest factor depending on major showed Natural sciences \& Engineering (NSE) ( $3.77 \pm 0.70$ point) was the highest, and Humanities and Social science (HSS) (3.68 \pm 0.77 point) and Arts, Music \& and Physical education (AMP) $(3.57 \pm 0.81$ point) were followed, but there was not statistically significant difference $(\mathrm{F}=1.324, \mathrm{p}=.267)$. In terms of expectation factor, the mean score in NSE major (3.43 \pm 0.87 point) was the highest, and $\operatorname{HSS}(3.34 \pm 0.84$ point $)$ and AMP (3.13 \pm 0.95 point) were followed, but there was not statistically significant difference $(\mathrm{F}=1.694, \mathrm{p}=.185)$. In terms of confidence factor, the mean score in NSE major (3.66 \pm 0.87 point) was the highest, and HSS $(3.61 \pm 0.85$ point $)$ and AMP (3.19 \pm 1.06 point) were followed, and the difference was statistically significant $(\mathrm{F}=3.719, \mathrm{p}=.025)$. The result of post-hoc analysis for mean difference in confidence factor showed AMP majoring students was statistically significant lower than that of NSE and HSS $(\mathrm{p}<.05, \mathrm{p}<.01)$. The result of analyzing difference in mean score of motivation factor depending on major showed the NSE majors $(4.25 \pm 0.72$ point) was the highest, and HSS majors ( $4.21 \pm 0.75$ point) were a little bit lower than NSE majors, and AMP majors $(3.91 \pm 0.81$ point) were the lowest, but there was not statistically significant $(\mathrm{F}=2.855, \mathrm{p}=.059)$. However, the result of post - hoc analysis for mean difference in motivation factor showed AMP majoring students was lower than NSE and HSS ( $\mathrm{p}<.05)$. In terms of anxiety factor,

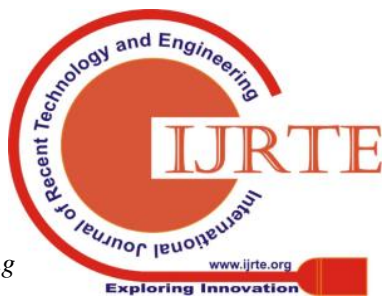


the mean score in AMP major (2.95 \pm 1.28 point) was the highest, and HSS $(2.51 \pm 1.11$ point $)$ and NSE $(2.35 \pm 1.06$ point) were followed, and the difference was statistically significant $(\mathrm{F}=4.221, \mathrm{p}=.015)$. The result of post - hoc analysis for mean difference in anxiety factor showed AMP majoring students was statistically significant higher than NSE and HSS $(\mathrm{p}<.05, \mathrm{p}<.01)$. Meanwhile, there was not a statistically significant difference in anxiety between NSE and HSS ( $>$ >.05).

Table- I: Differences in Variables IECMA Factors Depending on General Characteristics and Exposure to English

\begin{tabular}{|c|c|c|c|c|c|c|c|c|c|c|c|c|}
\hline & \multirow{2}{*}{ Characteristics } & \multirow{2}{*}{$\mathbf{n}$} & \multicolumn{2}{|c|}{ Interest } & \multicolumn{2}{|c|}{ Expectation } & \multicolumn{2}{|c|}{ Confidence } & \multicolumn{2}{|c|}{ Motivation } & \multicolumn{2}{|c|}{ Anxiety } \\
\hline & & & mean & $s d$ & mean & $s d$ & mean & $s d$ & mean & $s d$ & mean & $s d$ \\
\hline \multirow{3}{*}{ Gender } & male & 186 & 3.64 & 0.79 & 3.37 & 0.89 & 3.60 & 0.96 & 4.16 & 0.77 & 2.48 & 1.12 \\
\hline & female & 193 & 3.79 & 0.68 & 3.36 & 0.84 & 3.60 & 0.81 & 4.25 & 0.73 & 2.45 & 1.10 \\
\hline & \multicolumn{2}{|l|}{$\mathrm{t}(\mathrm{p})$} & \multicolumn{2}{|c|}{$-1.935(.054)$} & \multicolumn{2}{|c|}{$0.164(.870)$} & \multicolumn{2}{|c|}{$-0.018(.985)$} & \multicolumn{2}{|c|}{$-1.107(.269)$} & \multicolumn{2}{|c|}{$0.244(.808)$} \\
\hline \multirow{5}{*}{ Major } & $\begin{array}{l}{ }^{\mathrm{a}} \text { Natural sciences \& } \\
\text { Engineering }\end{array}$ & 189 & 3.77 & 0.70 & 3.43 & 0.87 & 3.66 & 0.87 & 4.25 & 0.72 & 2.35 & 1.06 \\
\hline & $\begin{array}{l}{ }^{\mathrm{b}} \text { Humanities and Social } \\
\text { science }\end{array}$ & 159 & 3.68 & 0.77 & 3.34 & 0.84 & 3.61 & 0.85 & 4.21 & 0.75 & 2.51 & 1.11 \\
\hline & $\begin{array}{l}{ }^{\mathrm{c}} \text { Arts, Music \& and Physical } \\
\text { education }\end{array}$ & 31 & 3.57 & 0.81 & 3.13 & 0.95 & 3.19 & 1.06 & 3.91 & 0.81 & 2.95 & 1.28 \\
\hline & \multicolumn{2}{|l|}{$\mathrm{F}(\mathrm{p})$} & \multicolumn{2}{|c|}{$1.324(.267)$} & \multicolumn{2}{|c|}{$1.694(.185)$} & \multicolumn{2}{|c|}{$3.719(.025)^{*}$} & \multicolumn{2}{|c|}{$2.855(.059)$} & \multicolumn{2}{|c|}{$4.221(.015)^{*}$} \\
\hline & \multicolumn{2}{|l|}{ post-hoc } & & & & & \multicolumn{2}{|c|}{$\mathrm{c}<\mathrm{b}^{*} \mathrm{c}<\mathrm{a}^{* *}$} & \multicolumn{2}{|c|}{$\mathrm{c}<\mathrm{b}^{*} \mathrm{c}<\mathrm{a}^{*}$} & \multicolumn{2}{|c|}{$c>b^{*} c>a^{* *}$} \\
\hline \multirow{6}{*}{$\begin{array}{l}\text { Exposure } \\
\text { to English }\end{array}$} & ${ }^{\mathrm{a}}$ Neither NS nor abroad & 94 & 3.53 & 0.81 & 3.17 & 0.86 & 3.22 & 0.95 & 4.02 & 0.79 & 2.79 & 1.16 \\
\hline & ${ }^{\mathrm{b}}$ Only experience with NS & 242 & 3.76 & 0.70 & 3.42 & 0.85 & 3.64 & 0.83 & 4.22 & 0.73 & 2.38 & 1.08 \\
\hline & ${ }^{\mathrm{c}}$ Only studying abroad & 6 & 4.03 & 0.45 & 3.33 & 0.47 & 3.42 & 0.52 & 4.22 & 0.70 & 2.88 & 0.70 \\
\hline & ${ }^{\mathrm{d}}$ Both NS and abroad & 37 & 3.86 & 0.74 & 3.56 & 0.93 & 4.29 & 0.60 & 4.56 & 0.57 & 2.14 & 1.02 \\
\hline & \multicolumn{2}{|l|}{$\mathrm{F}(\mathrm{p})$} & \multicolumn{2}{|c|}{$3.174(.024)^{*}$} & \multicolumn{2}{|c|}{$2.590(.053)$} & \multicolumn{2}{|c|}{$15.257(.000)^{* *}$} & \multicolumn{2}{|c|}{$4.929(.002)^{* *}$} & \multicolumn{2}{|c|}{$4.528(.004)^{* * *}$} \\
\hline & \multicolumn{2}{|l|}{ post-hoc } & \multicolumn{2}{|c|}{$a<b^{* *} a<d^{*}$} & \multicolumn{2}{|c|}{$\mathrm{a}<\mathrm{b}^{*} \mathrm{a}<\mathrm{d}^{* *}$} & $a<b^{* * *} \cdot d^{* * *}$ & $d^{* * *} b<$ & $\begin{array}{c}a<b \\
b\end{array}$ & $\mathrm{Kd}^{* * *}$ & & \\
\hline
\end{tabular}

$* \mathrm{p}<.05, * * \mathrm{p}<.01$

Meanwhile, in Park's study [7], Humanities and Social Science majors showed higher interest than Natural Science and Engineering majors in interest factor, and the result was statistically significant. However, Art, Music, and Physical education majors showed lowest in every affective factor [7, 12], which are accord with result of the research.

\section{E.Mean score differences in IECMA factors depending on Exposure to English major}

As shown table 1, the result of analyzing difference in mean score of interest factor depending on exposure to English showed studying abroad students (ABROAD) (4.03 \pm 0.45 point) was the highest, and both native speakers and abroad experience (Both) (3.86 \pm 0.74 point), only experience with native speakers (NS) $(3.76 \pm 0.70$ point), and neither NS nor abroad (NONE) were followed, and the difference was statistically significant $(\mathrm{F}=3.174, \mathrm{p}=.024)$. The result of post hoc analysis for mean difference in interest factor showed interest of NONE was statistically significant lower than that of NS and BOTH $(\mathrm{p}<.01, \mathrm{p}<.05)$. In terms of expectation factor, the mean score in BOTH $(3.56 \pm 0.93$ point) was the highest, and NS (3.42 \pm 0.85 point), ABROAD (3.33 \pm 0.47 point), and NONE ( $3.17 \pm 0.86$ point) were followed, but there was not statistically significant $(\mathrm{F}=2.590, \mathrm{p}=.053)$.

However, The result of post - hoc analysis for mean difference in expectation factor showed expectation of NONE was statistically significant lower than that of NS and BOTH $(\mathrm{p}<.05, \mathrm{p}<.01)$. In terms of confidence factor, the mean score in BOTH $(4.29 \pm 0.60$ point) was the highest, and NS (3.64 \pm 0.83 point), ABROAD (3.42 \pm 0.52 point), and NONE (3.22 \pm 0.95 point) were followed, and the difference was statistically significant $(\mathrm{F}=15.257, \mathrm{p}=.000)$. The result of post
- hoc analysis for mean difference in confidence factor showed confidence of NONE was statistically significant lower than that of NS and BOTH $(\mathrm{p}<.01, \mathrm{p}<.01)$, confidence of NS was statistically significant lower than that of BOTH $(\mathrm{p}<.01, \mathrm{p}<.01)$, and confidence of ABROAD was statistically significant lower than that of BOTH $(\mathrm{p}<.01, \mathrm{p}<.01)$. In terms of motivation factor, the mean score in BOTH $(4.56 \pm 0.57$ point) was the highest, and NS and ABROAD were same (4.22 \pm 0.73 point), and NONE (4.02 \pm 0.79 point) was the lowest, and the difference was statistically significant $(\mathrm{F}=4.929, \mathrm{p}=.002)$. The result of post - hoc analysis for mean difference in motivation factor showed motivation of NONE was statistically significant lower than that of NS and BOTH $(\mathrm{p}<.05, \mathrm{p}<.01)$, motivation of NS was statistically significant lower than that of BOTH ( $\mathrm{p}<.01)$. In terms of anxiety factor, the mean score in ABROAD (2.88 \pm 0.70 point) was the highest, and NONE $(2.79 \pm 1.16$ point $)$, NS $(2.38 \pm 1.08$ point $)$, and BOTH $(2.14 \pm 1.02$ point $)$ were followed, and the difference was statistically significant $(\mathrm{F}=4.528, \mathrm{p}=.004)$. The result of post - hoc analysis for mean difference in anxiety factor showed anxiety of NONE was statistically significant higher than that of NS and BOTH $(\mathrm{p}<.01, \mathrm{p}<.01)$.

Meanwhile, discussion for effect on studying abroad is very argumentative, Lee [13] showed development of English ability through study abroad, on the other hand, Rha [14] showed the development for motivation and English ability through domestic English camp, and she insisted domestic English camp is more effective in economical and students' psychological factors. 
Table- I: Relationship between affective factors focusing on motivation

\begin{tabular}{|c|c|c|c|c|c|c|c|}
\hline Variables & $\mathrm{B}$ & $\mathrm{SE}$ & $\beta$ & $\mathrm{t}$ & $\mathrm{p}$ & $\begin{array}{c}\text { Adjusted } \\
\mathrm{R}^{2}\end{array}$ & $\mathrm{~F}(\mathrm{p})$ \\
\hline (Constant) & 1.896 & .296 & & 6.396 & .000 & .238 & $\begin{array}{c}29.174 \\
(.000)\end{array}$ \\
\hline Interest & .161 & .069 & .160 & 2.353 & .019 & & \\
\cline { 1 - 6 } Expectation & .167 & .054 & .193 & 3.077 & .002 & & \\
\hline Confidence & .265 & .055 & .315 & 4.781 & .000 & & \\
\hline Anxiety & .079 & .041 & .117 & 1.906 & .057 & & \\
\hline
\end{tabular}

anxiety factor, and expectation statistically significant in post

\section{F. Relationship between affective factors focusing on motivation}

To identify factors affecting on motivation, a multiple linear regression analysis was used. As shown table 2, among all the variables, confidence $(\beta=0.315, p=.000)$ was most influential on motivation, and expectation $(\beta=0.193, p=.002)$, interest $(\beta=0.160 \mathrm{p}=.019)$, and anxiety $(\beta=0.117, \mathrm{p}=.218)$ had effects on motivation in order. The total explanatory power was $23.8(\mathrm{~F}=29.174, \mathrm{p}=.000)$.

On previous study for factors affecting motivation [5], confidence factor was the most influential, which was agreement with the result of the research. Also, interest was the third influential factor, and anxiety was the fourth influential factors, which was accord to the result of the research.

\section{CONCLUSION}

This study proposed to find out factors affecting English learning depending on gender, major, and exposure to English, and investigate relationship between affective factors and which factor is more influential to learning motivation. The subjects were 379 freshmen at a regional university in Korea, who registered mandatory communicative English class managing by team-teaching with native speakers and Korean professors. The method of the research was a descriptive survey composed with both a check list asking for participant's general characteristics, and exposure to English and a questionnaire asking for students' interest, expectation, confidence, motivation and anxiety in communicative English class. Collected data was analyzed with SPSS Statistics, and the results were as follows:

First, in terms of students' general characteristics, there was not shown statistical significance depending on gender, however, female students showed higher interest and motivation than male students, and male students showed higher expectation and anxiety than female students. There were few studies for gender difference among affective factors, but in a statistically significant study, there showed female students were higher than male students in motivation factor. This suggests a more accurate follow-up research is needed between genders. As for major, there were statistically significant in confidence and anxiety factors, and motivation $\&$ Physical education majors showed lower confidence and motivation, and higher anxiety than Natural Science \& Engineering majors and Humanities and Social Science majors.

Second, in regard to exposure English, there were statistically significant in interest, confidence, motivation and was statistically significant in post - hoc analysis. Art, Music,

- hoc analysis. The students who had experience with native speakers between elementary school and high school showed higher interest, expectation, confidence, motivation and lower anxiety than none of exposure to English. On the other hand, the students who had experience with native speakers showed lower interest and anxiety, and higher expectation and confidence than students who had studies abroad, and motivation was same in both groups.

Third, in terms of relationship between affective factors focusing on learning motivation, confidence was a most influential factor. And expectation, interest, and anxiety had effects on learning motivation in order.

The research had limitation that all freshmen did not participate in the survey, and did not reflect all students' opinions, but it is meaningful to try to find out students' characteristics depending on gender, major, exposure to English, and more influential factor on learning motivation to provide better effective communicative English class.

The research result suggests the proposal to improve students' participation in communicative English class. First, approaching method has to be different depending on majors. Especially, art, music \& physical education majors showed lowest interest, confidence, motivation and highest anxiety. They had less exposure to English because of their major. A textbook and contents could be difficult for them, and it might lessen their enthusiasm for English. Thus, teaching materials related in art, music or physical education is to be provided for them, and teaching approach is to be considered appropriately for their physical and psychological characteristics. Second, depending on exposure to English, students' affective factors were different. Contrary to expectations, the students who had experience with native speakers showed higher confidence and motivation combined with lower anxiety than those who had experience studying abroad. This implicates that it will be possible to succeed in English acquisition even studying domestically. Studying in domestic environment could be more efficient in regard of students' economical, physical, and psychological parts. To support students who study English in domestic environment, more various and better English classes are to be prepared and provided. Lastly, under same teacher, same curriculum, or same learning environment, the reason for different progress between students could be found in the students' motivational difference. If student's motivation is increased, their accomplishment will be also increased.

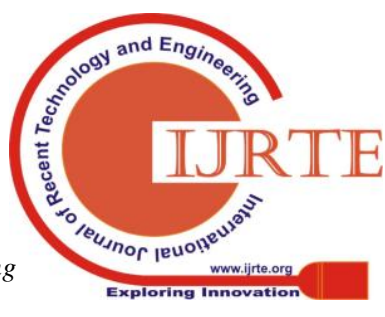


Learning strategy and access to increase students' motivation has to be developed. And the most influential factor on motivation was confidence. Those who are in a local or regional university tend to have lower confidence due to their experience of failure. The English education programs can inspire their confidence have to be developed.

In short, the study suggests to develop an efficient and systematic communicative English class appropriate for students at a regional university in Korea.

\section{ACKNOWLEDGMENT}

This work was supported by the research grant of Pai Chai University in 2019.

\section{REFERENCES}

1. S. Krashen, Principles and practice in second language acquisition. New York: Oxford University Press, 1982.

2. R. C. Gardner, W. Lambert, Attitude and motivation in second language learning. Rowley, Mass: Newsbury House, 1972.

3. Z. Dörnyei, E. Ushioda, Motivation, language identities, and the L2 self. Toronto: Multilingual Matters, 2009.

4. DH. Kang, "The gender role in L2 motivation of Korean university students," Korea Journal of English Language and Linguistics, 15(2), June 2015, pp. 305-325. Available:http://www.dbpia.co.kr/Article/NODE06383367

5. OJ. Kim, SH. Park, "Analysis trends on intervention studies in English learning motivation: based on domestic journals published from 2008 to 2017," Journal of Learner-Centered Curriculum and Instruction, 18(11), June 2018, pp. 635-663. Available:http://dx.doi.org/10.22251/jlcci.2018.18.11

6. MH. Shin, KH. Kim, "Factors affecting English learners' learning motivation," Journal of Digital Convergence, 10(9), May 2012, pp 443-448. Available:http://www.riss.kr/link?id=A99540981

7. OH. Park, "A study on the effective general English program through team-teaching of native and Korean teachers," The Journal of Foreign Studies, 31,March2015,pp. 41-70. Available:http://dx.doi.org/10.15755/jfs.2015.31.41

8. YS. Kim, "University students' motivation, needs and expectations of general English education," Journal of the Applied Linguistics Association of Korea, 11, June 1996, pp. 73-98. Available:http://www.riss.kr/link?id=A60147656

9. DS. Chong, HD. Kim, "A study for the development of a university level general English course,” English Teaching, 56(4), December 2001, pp. 265-292. Available: http://www.riss.kr/link?id=A104570495

10. TY. Kim, "Motivation and attitudes toward foreign language learning as socio-politically mediated constructs: the case of Korean high school students," The Journal of Asia TEFL, 3(2), June 2006, pp. 165-192. Available:http://www.riss.kr/link?id=A60231751

11. HO. Kim, HK. Lee, "A study of students' and teachers' perceptions toward level-differentiated general English classes in the university," English Teaching, 64(4), December2010, pp. 337-368. Available:http://www.riss.kr/link?id=A104570671

12. MH. Yoon, "A study on art theory education in the Art \& Design College using English medium instruction (EMI)," Society for Art education of Korea, 34, March2009, pp. 1-39. Available:http://www.riss.kr/link?id=A100049515

13. YM. Lee, "A study on the effects and influences of study abroad program on English learning," The Journal of Mirae English Language and Literature, 15(1), April 2010, pp. 139-155. Available:http://www.dbpia.co.kr/Article/NODE06686063

14. KH. Rha, "Correlational analysis between types of learning motivation of Korean EFL college students in the English camp and their English proficiency," The Jungang Journal of English Language \& Literature, 53(1), March 2011, 159-177. Available:http://www.riss.kr/link?id=A82595622

\section{AUTHORS PROFILE}

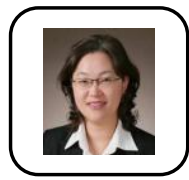

Prof.Weon-Hee Moonis currently working at Department of Nursing Science/Pai Chai University. Experienced in Hospital Information System Development from 1998 until 2014at the ChungnamNational University Hospital in Korea.Received $\mathrm{PhD}$ in Nursing Science/Informatics from Chungnam National University. Having 27 Publications in Journals.Research interest includes Convergence of IT \& Health care, instructional technology, and e-Learning.

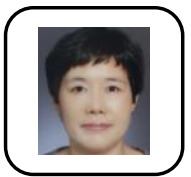

Ok Hee Parkis a professor at the Pai Chai University in South Korea, and she is teaching English in Liberal Arts division. She obtained her Master degree in State University of New York (SUNY) at Albany, and Ed.D in Korea National University of Education(KNUE), Korea. Her research interests are in English as a Foreign Language (EFL), instructional technology. Her core academic teaching includes English grammar, reading, writing for undergraduate students. 